\title{
Localization of Pyroantimonate-Precipitable Calcium in the Vestibular Organs of the Rat and Guinea Pig*
}

\author{
Seiichi KAWAMATA \\ Department of Anatomy, Toyama Medical and Pharmaceutical University, Toyama, Japan
}

Received November 1, 1990

\begin{abstract}
Summary. Localization of pyroantimonate-precipitable calcium (Ca) was examined in the vestibular organs of the rat and the guinea pig. Precipitates were observed around the otoconia and in the otolithic membranes of the macula sacculi and macula utriculi. Although the deposition was heavier in the rat than in the guinea pig, the distribution of the Ca-pyroantimonate was similar in both species. Most otoconia in the dark cell area had precipitates around and inside the otoconia. Furthermore, there was some precipitation in the cupulae of the semicircular canals in both animals. The presence of $\mathrm{Ca}$ in the precipitates was confirmed by $\mathrm{X}$-ray microanalysis and extraction with EGTA. Localization of the Ca-pyroantimonate around the otoconia in these animals agrees with localization of precipitates of endolymphatic crystals in the tree frog, which are known to grow mainly by accretion. Thus, the otoconia of the rat, and probably also of the guinea pig, can be assumed to grow mainly by accretion.
\end{abstract}

Otoconia are calcium carbonate $\left(\mathrm{CaCO}_{3}\right)$ crystals in the inner ear, and serve as an element of the gravity receptor organs. It is well known that bony fish possess a single otoconium. In the fish otoconium, there are concentric rings which represent its growth and thus can be used in determining age (PANNELL, 1971; LIM, 1974, 1984). In contrast, amphibians and higher vertebrates have numerous otoconia. In the tree frog, for example the endolymphatic $\mathrm{CaCO}_{3}$ crystals which resemble otoconia have been demonstrated to grow by accretion and fusion (KAWAMATA, 1987a, b, 1990a, b). In the chick embryo, BALSAMO et al. (1969) postulated that otoconia are formed by accretion and fusion in the endolymphatic sac and transported to the otolithic organs. BALLARINO and HowlAND (1982) believed that chick otoconia pass through growth sequences for maturation, and that the size of otoconia may depend on the duration of the filling out (mineralization) stage or on the initial amount of the organic matrix. In mammals, little is known about the formation mechanism of otoconia, with several hypotheses proposed. BÉLANGER (1960), ROSS and PEACOR (1975) reported that otoconia are formed by accretion and fusion. NAKAHARA and BEVELANDER (1979) suggested that the organic matrix aggregates to form primitive otoconia (preotoliths) which determine the size and shape of the future otoconia. They considered the mineralization to start after the formation of the preotolith. HARADA (1978), ANNiKo (1980), HARAdA and TAGASHIRA (1981) claimed that globules or granules containing $\mathrm{Ca}$ are secreted from supporting and/or sensory epithelial cells and the excreted substance transforms into otoconia. All these hypotheses were mainly based on light and electron microscopic observations and X-ray microanalysis of fixed specimens with or without decalcification. Few attempts have been made to visualize $\mathrm{Ca}$ ion in the inner ear (FERMIN and IGARASHI, 1985). One of the major problems of localizing $\mathrm{Ca}$ ion in the inner ear derives from the fact that otoconia are so hard that it is difficult to cut them into ultrathin sections. If otoconia are decalcified with acids or chelators to allow easier sectioning, not only otoconia but also the Ca precipitates are dissolved. However, this problem has now been partly overcome by application of a selective demineralization technique, and pyroantimonate-precipitable $\mathrm{Ca}$ has been successfully demonstrated in the endolymphatic sac of the tree frog (KAWAMATA, 1990b) where $\mathrm{CaCO}_{3}$ crystals are formed. Using the same method, an attempt has now been made to visualize pyroantimonate-precipitable $\mathrm{Ca}$ in the vestibular organs of the rat and the guinea pig.

\footnotetext{
*This study was supported by a grant (No. 02807002) from the Ministry of Education, Science and Culture, Japan.
} 


\section{MATERIALS AND METHODS}

Ten 2-week-old and five 8-week-old Sprague-Dawley rats (males and females) and thirteen Hartley guinea pigs (males, body weight between 180 and $280 \mathrm{~g}$ ) were anesthesized with ether. They were perfused through the left ventricle first with saline and then with a fixative that contained $3 \%$ glutaraldehyde and $2 \%$ potassium pyroantimonate in $0.1 \mathrm{M}$ potassium phosphate buffer ( $\mathrm{pH}$ 7.4). The inner ears were immediately removed and stored in the same fixative. Vestibular organs, dissected out from the inner ears in the fixative under a stereomicroscope, were further immersed in the fixative for a total of 4 to $9 \mathrm{~h}$. The macula sacculi, macula utriculi and semicircular canals were postfixed overnight in a solution of $2 \%$ potassium pyroantimonate and $1 \% \mathrm{OsO}_{4}$. Following this, the otolithic organs were rinsed once with $10 \%$ saccharose, demineralized in $2 \%$ ammonium chloride $\left(\mathrm{NH}_{4} \mathrm{Cl}\right)$ for 1 to 3 weeks at $4^{\circ} \mathrm{C}$, and rinsed three times with $10 \%$ saccharose. They were dehydrated with an ascending series of ethanol, soaked in propylene oxide, and embedded in epoxy resin. The ampullae of semicircular canals and some otolithic organs, whose otoconia had been removed by a stream of the fixative from a small syringe, were not subjected to demineralization but were processed in the same manner as described above in order to avoid a possible loss of precipitates during the demineralization with $\mathrm{NH}_{4} \mathrm{Cl}$. Ultrathin sections were cut, stained with uranyl acetate and lead citrate, and observed under a JEM-100S transmission electron microscope.

\section{Treatment of ultrathin sections with EGTA}

EGTA (ethylene glycol-bis [ $\beta$-aminoethyl ether] N, $\mathrm{N}, \mathrm{N}^{\prime}, \mathrm{N}^{\prime}$-tetraacetic acid) was used to examine whether or not the precipitate contained Ca. EGTA is a chelator which has an affinity for Ca. Some ultrathin sections were examined first under the electron microscope and then were again examined after immersion in 4\% EGTA adjusted to $\mathrm{pH} 8.0$ with potassium hydroxide, for $1 \mathrm{~h}$ at $60^{\circ} \mathrm{C}$ (modified from WICK and HEPLER, 1982).

\section{$X$-ray microanalysis}

Semithin sections (about $0.75 \mu \mathrm{m}$ in thickness) were cut, collected on collodion-coated copper grids, coated with carbon, and X-ray microanalysed under a Hitachi X-650 analytical electron microscope equipped with a Kevex 7000 energy dispersive spectrometer (EDS) and a Hitachi S-6091 wavelength dispersive spectrometer (WDS). The conditions for operation of the EDS were an accelerating voltage of $40 \mathrm{kV}$, probe diameter about $0.5 \mu \mathrm{m}$, probe current $4-6 \mathrm{nA}$, and counting time $100 \mathrm{sec}$. The WDS was used for the reason that the EDS does not have sufficient resolving power to separate the $\mathrm{L} \alpha$ line of antimony (Sb) and the $\mathrm{K} \alpha$ line of $\mathrm{Ca}$. The conditions for operation of the WDS were an accelerating voltage of $40 \mathrm{kV}$, probe diameter about $0.5 \mu \mathrm{m}$, and probe current $4-6 \mathrm{nA}$.

\section{RESULTS}

During fixation and postfixation, a small number of cupulae from the rats and guinea pigs turned white and turbid. Otoconia gradually became invisible during the demineralization. One week was sufficient for demineralization of the otoconia.

\section{Demineralized otolithic organs}

The rat otoconia were covered by a thick, electrondense layer. Numerous deposits of varying sizes were densely packed in the rat otolithic membranes (Fig. 1). In the guinea pig, the extent of precipitation was weak around the otoconia, and particles of precipitate were scattered in the otolithic membranes (Fig. 2). Although the extent of precipitation was lower in the guinea pig, the distribution of precipitate corresponded to that in the rat. The macula sacculi and macula utriculi showed the same results in both species. The extent of precipitation varied somewhat from one experiment to another. The precipitate was occasionally found along the cell membrane and sensory hairs of the epithelia; however, the precipitate seemed randomly distributed in the cytoplasm of the sensory epithelial cells of the rat (Fig. 1) and the guinea pig.

\section{Otolithic organs not demineralized}

The extent and the distribution of precipitates in the sensory epithelium of the rat and the guinea pig resembled those in demineralized samples (Fig. 3).

\section{Ampullae of semicircular canals that were not demineralized}

Most otoconia in the dark cell area of the rat and the guinea pig had precipitates not only around the otoconia but also inside them (Fig. 4). Otoconia without precipitates were occasionally encountered. A small amount of precipitate was sometimes observed along the cell membrane in the supporting and hair cells. However, no close relationship was evident 
between precipitates in the cytoplasm and any kind of organelle in these cells. By contrast, in a few cupulae of the rat and the guinea pig, there were numerous deposits of precipitate (Fig. 5).

\section{Treatment of ultrathin sections with EGTA}

Nearly all the precipitates in the otolithic organs and semicircular canals in the rat and the guinea pig were extracted by EGTA (Fig. 6). Incubation for the same amount of time in distilled water at $60^{\circ} \mathrm{C}$ resulted in some extraction of precipitates, but most were preserved.

\section{$\mathrm{X}$-ray microanalysis}

High, clear peaks of X-ray lines of $\mathrm{Ca} \mathrm{K} \alpha$, and $\mathrm{Sb}$ $\mathrm{L} \alpha, \mathrm{Sb} \mathrm{L} \beta_{1}$ were recorded with the WDS from the

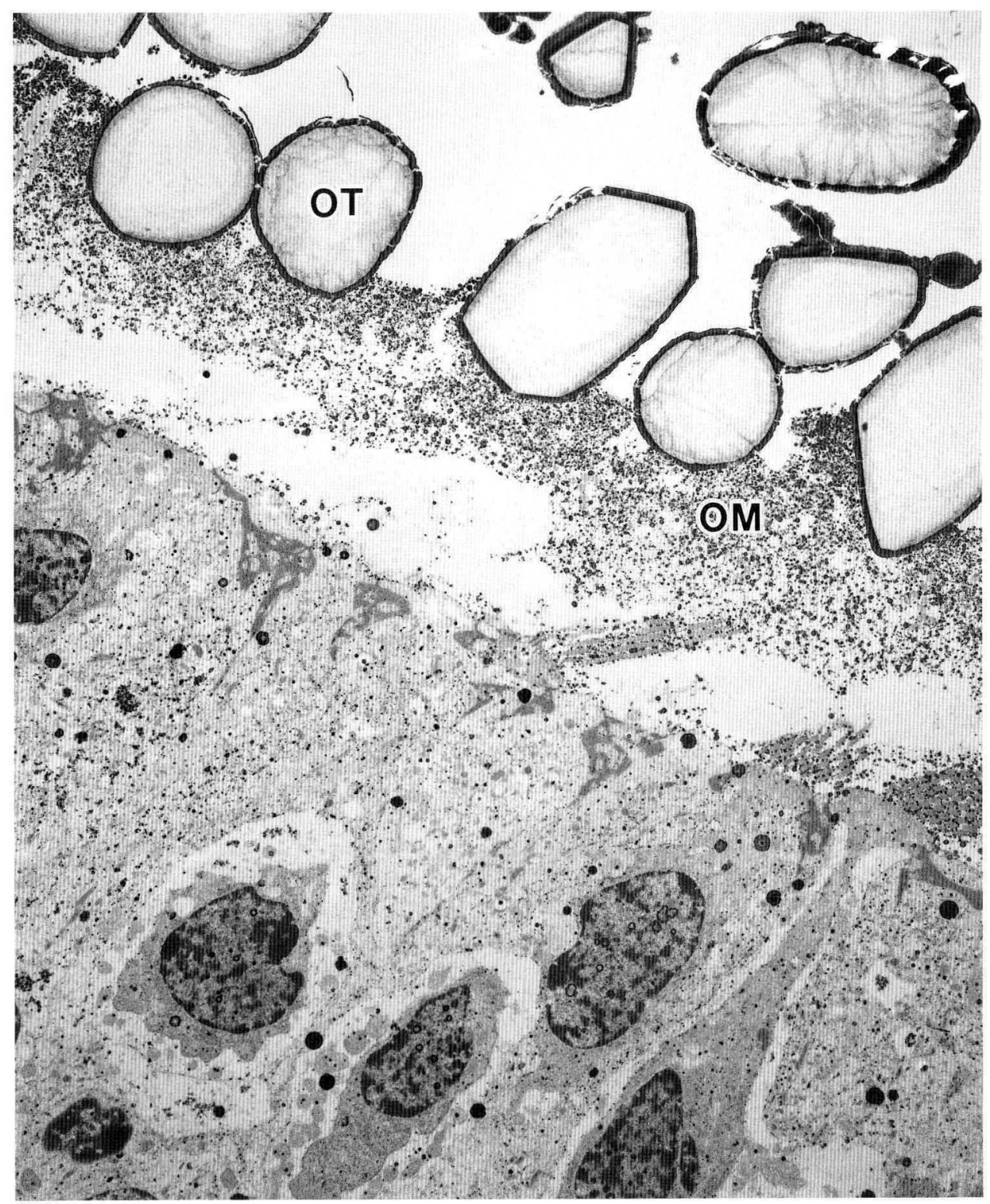

Fig. 1. The macula utriculi of an 8-week-old rat. A thick layer of precipitate around otoconia $(O T)$ and numerous deposits in the otolithic membrane $(O M)$ can be seen. Precipitate is randomly distributed in the sensory epithelium. Demineralized. $\times 3,000$ 


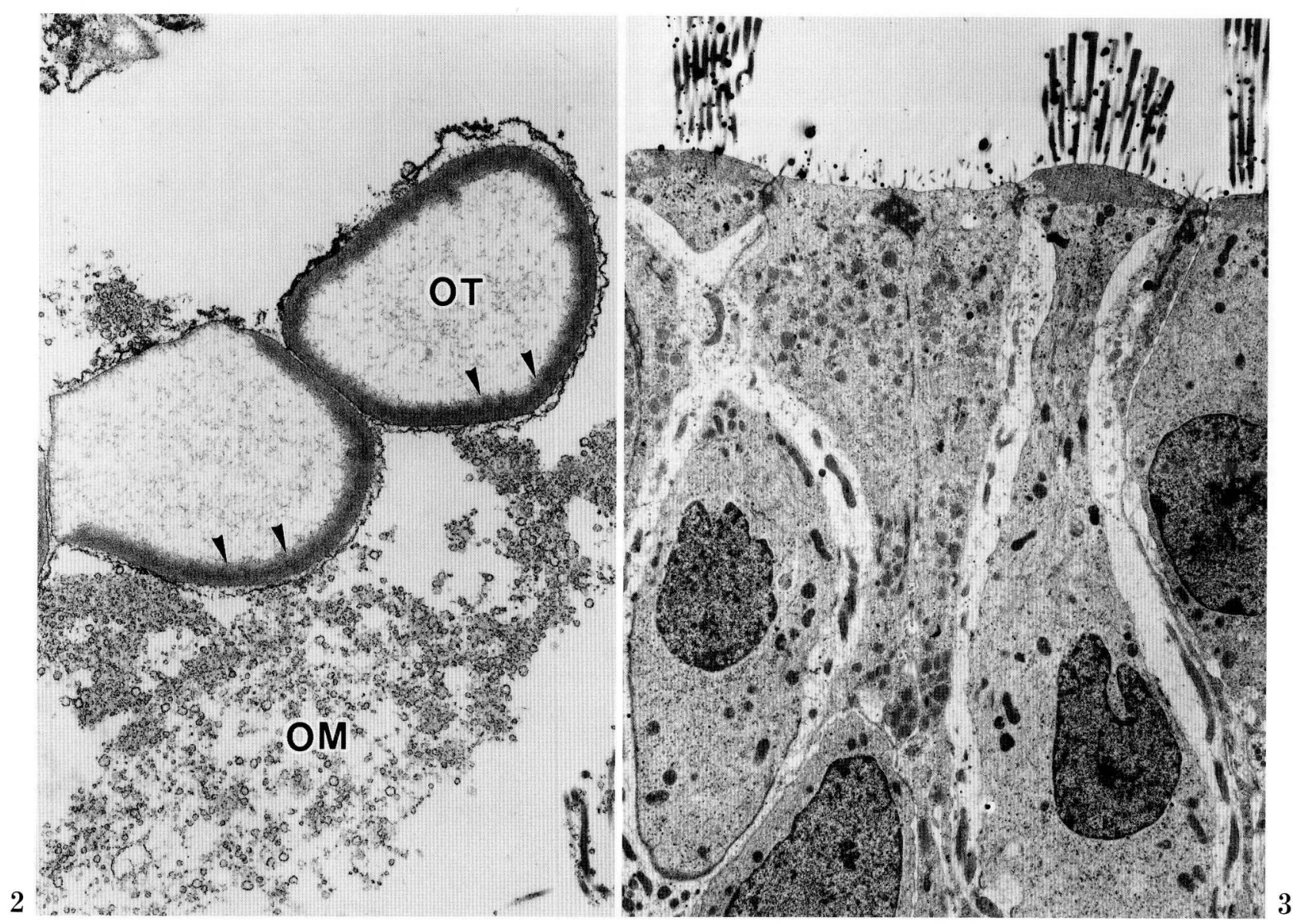

Fig. 2. Otoconia in the macula utriculi of a guinea pig. Sparse deposition of precipitate can be observed around the otoconia $(O T)$ and in the otolithic membrane $(O M)$. The organic matrix (arrowheads) in the periphery of these otoconia has no precipitate since it was embedded in $\mathrm{CaCO}_{3}$ and separated from the fixative and the postfixative. Demineralized. $\times 7,000$

Fig. 3. The sensory epithelium in the macula utriculi of a 2 -week-old rat. The precipitate seems to be associated with sensory hairs but not with organelles in the cytoplasm. Not demineralized. $\times 3,700$

electron-dense precipitate in the rat otolithic organs (Fig. 7a, b). Low peaks, including $\mathrm{Ca} \mathrm{K} \alpha$, were also detected from the precipitate in the otolithic organs of the guinea pig. Depositions in the cupulae of the rat and the guinea pig were also shown to contain $\mathrm{Ca}$ by use of the WDS. Neither $\mathrm{Ca}$ nor $\mathrm{Sb}$ was detected in areas which were devoid of precipitates. The so-called organic matrix, distributed unevenly inside and around the otoconia, was not very clear under the analytical electron microscope. The organic matrix inside the otoconia of the rat and the guinea pig was found to contain varying amounts of sulfur by use of the EDS (Fig. 8). However, the otolithic membrane, the localization of which was judged by the presence of precipitates, was found to contain in both animals little or no sulfur under identical conditions.

\section{DISCUSSION}

To the author's knowledge, this is the first investigation of the localization of pyroantimonate-reactive $\mathrm{Ca}$ in the mammalian inner ear. The mechanism by which otoconia are demineralized is explained by the following chemical reaction (CHITANI, 1959):

$\mathrm{CaCO}_{3}+2 \mathrm{NH}_{4} \mathrm{Cl}=\mathrm{CaCl}_{2}+2 \mathrm{NH}_{3}+\mathrm{CO}_{2}+\mathrm{H}_{2} \mathrm{O}$

The presence of $\mathrm{Ca}$ in the precipitate was verified by use of X-ray microanalysis (WDS), and most precipitates were extracted by 4\% EGTA. These findings prove that the main cation in the precipitate was Ca.

FERMIN and IgARASHI (1985) have attempted to localize pyroantimonate-precipitable $\mathrm{Ca}$ in the otolithic organs of the embryonic chick. They observed 


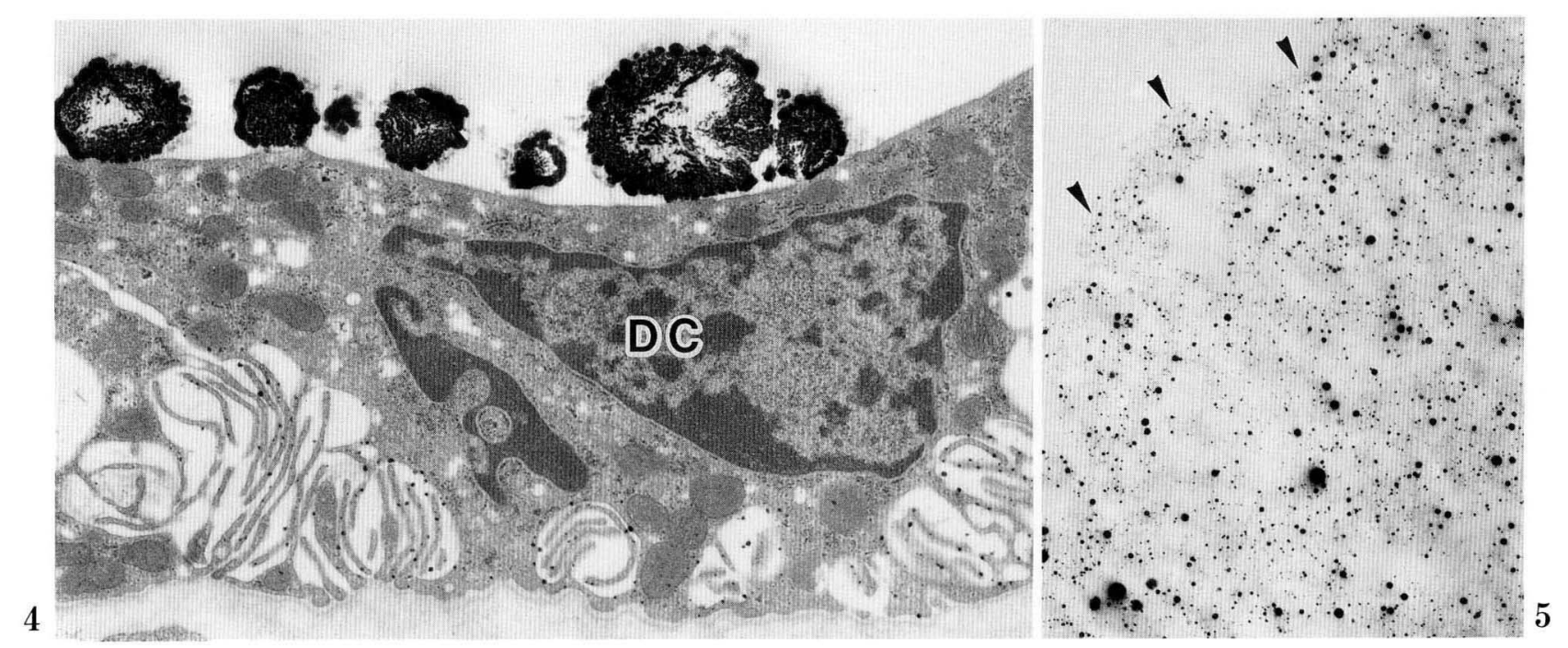

Fig. 4. Otoconia in the dark cell area of a guinea pig semicircular canal. Precipitate is evident around as well as inside otoconia. Not demineralized. $D C$ dark cell. $\times 11,000$

Fig. 5. The cupula with precipitates in the guinea pig semicircular canal. Particles of precipitate, varying both in number and in size, can be seen in the cupula, the margin of which is indicated by arrowheads. Not demineralized. $\times 5,600$

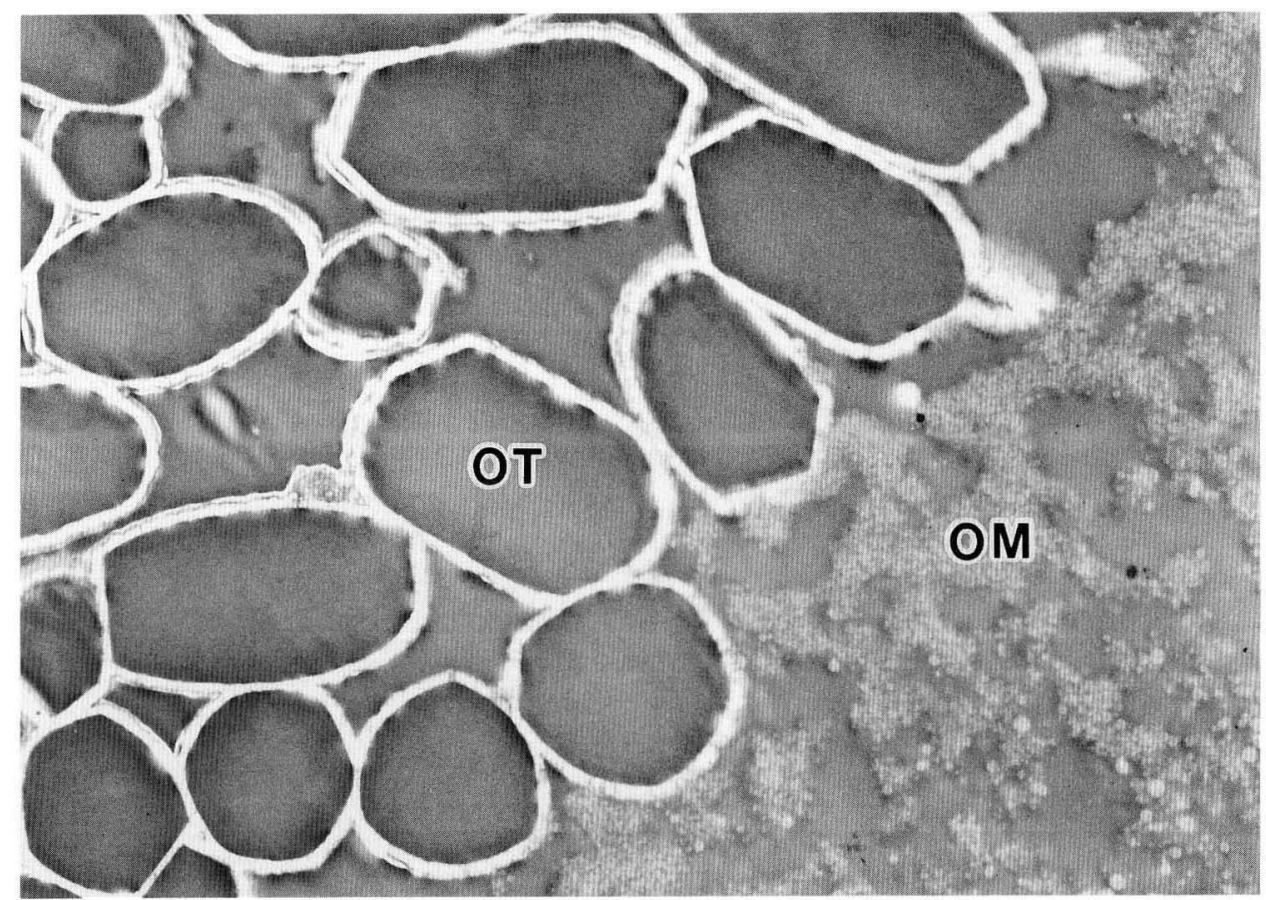

Fig. 6. A section of the macula utriculi of a 2-week-old rat treated with EGTA. The precipitate around the otoconia $(O T)$ and in the otolithic membrane $(O M)$ has been extracted. Demineralized. $\times 3,700$ 


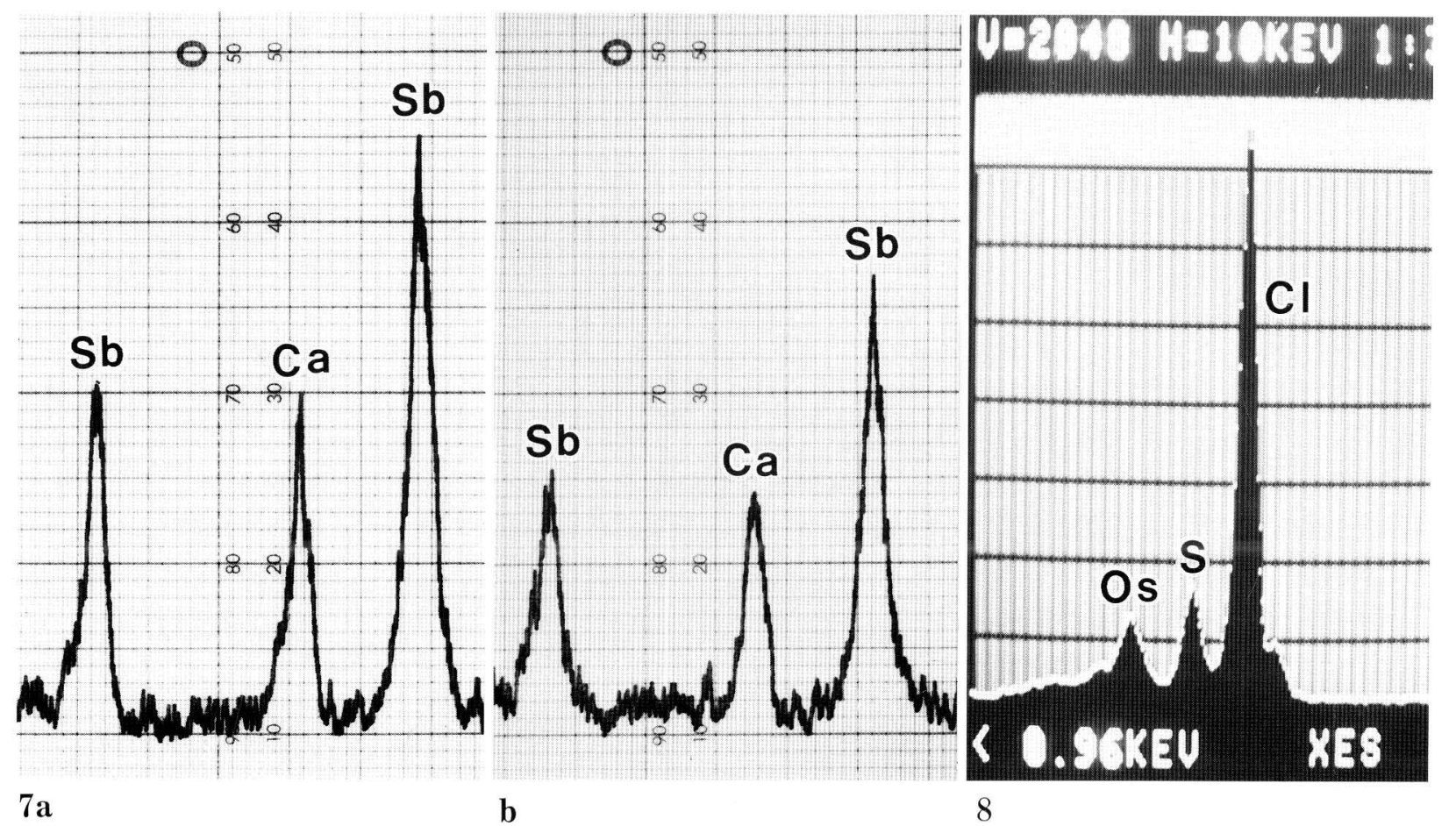

Fig. 7. Results of analysis with the WDS of the precipitate in the macula utriculi of an 8-week-old rat. Peaks from right to left, Sb L $\alpha$, Ca K $\alpha$, Sb L $\beta_{1}$, respectively. Ordinate: X-ray intensity, abscissa: wavelength. a. Results for precipitates around the otoconia. b. Results for precipitates in the otolithic membrane.

Fig. 8. Results of analysis with the EDS of the organic matrix inside otoconia in the macula utriculi of an 8 -week-old rat. Sulfur $(S)$ is clearly visible. $\mathrm{Cl}$ chlorine in the epoxy resin, Os osmium

a small number of minute granules on the surface of developing otoconia. The paucity of precipitate in their experiment, as compared with the present study, may be attributable to differences in the material and/or methods used. The difference in the intensities of reactions between the rat and the guinea pig in the present study may be a species difference, since the extent of precipitation was almost equal in rats of different ages ( 2 and 8 weeks of age).

The present study demonstrated that the otoconia of the rat and the guinea pig are surrounded by an organic matrix which has an affinity for Ca ion. The precipitate was clearly demonstrated around the otoconia and in the otolithic membrane. On the contrary, the precipitate within the sensory epithelium was slight even in the specimens without $\mathrm{NH}_{4} \mathrm{Cl}$ treatment, and had no significant relationship with any cell organelle (Fig. 3). This finding clashes with the high Ca content in the sensory epithelium (HARADA, 1978; ANNIKo, 1980; HARAdA and TAGASHIRA, 1981), although the species and/or age of the animals are different. Similarly, the endolymphatic crystals of the tree frog are surrounded by a dense material which has an affinity for $\mathrm{Ca}$ ion, but show little precipitate within epithelial cells (KAWAMATA, 1990b). The dense material in the tree frog is considered to play an important role in the additional growth of the endolymphatic crystals (KAWAMATA, 1987a, b, 1990a, b). The dense material is very similar to the so-called organic matrix of the mammalian inner ear. It has been repeatedly stressed that the organic matrix is important in the process of the formation of otoconia (BÉlanger, 1960; Veenhof, 1969). Bélanger (1960) stated that rat otoconia are covered by an organic matrix and grow by accretion and fusion. The idea that otoconia grow by accretion and fusion was also suggested by Veenhof (1969) and Ross and Peacor (1975), in the mouse and in the rat, respectively. Thus, the author is tempted to speculate that the otoconia of the rat, and probably of the guinea pig too, grow mainly by accretion, as do the endolymphatic crystals of the tree frog. This means that the formation of the organic matrix and mineralization occur concurrently regardless of the shape and size of the otoconia. 
It is noteworthy that fusion and accretion are not different but rather similar processes. Otoconia seem to grow by accretion when they are separated from one another by the organic matrix. However, otoconia happen to fuse if the intervening organic matrix is greatly diminished or lacking (Ross and PEACOR, 1975). In both processes, the organic matrix plays a key role in mineralization. The insufficiently separated otoconia probably allow a Ca deposition between their surfaces, and so fuse. Evidence has shown that the tightly-packed $\mathrm{CaCO}_{3}$ crystals often form conglomerated (fused) crystals in the endolymphatic sac of the tree frog when crystal production was accelerated (KAWAMATA, 1990a).

The precipitate around the otoconia seems to indicate the constant removal and redeposition of $\mathrm{CaCO}_{3}$ at the otoconial surface (ROSS and PEACOR, 1975). However, it was difficult to judge whether or not the otoconia were growing in the animals used in this study. Radioactive ${ }^{45} \mathrm{Ca}$ has been applied to examine the Ca turnover of the otoconia (and the otolithic membranes), but with mixed results (BÉLANGER, 1960; VeENHOF, 1969; Preston et al., 1975; Ross, 1979; MEChigian et al., 1979). BÉLANGER (1960) and VEEN HOF (1969) examined the incorporation of ${ }^{45} \mathrm{Ca}$ into otoconia by light microscopic autoradiography using rats (3 to 9 days old) and mice (perinatal and adult), respectively. In animals aged 2 days or older, they observed little or no incorporation of ${ }^{45} \mathrm{Ca}$ into the otoconia. On the other hand, PRESTON et al. (1975), Ross (1979) and Mechigian et al. (1979) found the incorporation of ${ }^{45} \mathrm{Ca}$ into otoconia by liquid scintillation counting using young gerbils, adult rats and young guinea pigs, respectively. PRESTON et al. (1975) calculated the half life of the $\mathrm{Ca}$ in otoconia of the gerbil to be 11.3 days. Although the incorporation of ${ }^{45} \mathrm{Ca}$ into otoconia was slow and scanty, Ross (1979) and MECHIGIAN et al. (1979) concluded that otoconia are dynamic structures. HARADA and TAGASHIRA (1981) observed the regeneration of otoconia within 2 months in the streptomycin-treated guinea pig. The turnover of $\mathrm{Ca}$ in mammalian otoconia needs further study.

It is interesting that precipitated Ca-pyroantimonate was found in the otolithic membrane and cupula where otoconia are not formed. The otolithic membrane and cupula seem to have, to a greater or lesser extent, an affinity for $\mathrm{Ca}$ or possibly other cations. However, their functional role in biomineralization is unknown at present.

Most otoconia in the dark cell area had precipitates around them as well as inside them. Such otoconia were not found in the macula sacculi and macula utriculi. This observation seems to support the hypothesis that otoconia are decalcified in the dark cell area (LIM, 1973; HARADA and TAGASHIRA, 1981). Decalcified otoconia probably allow the penetration of pyroantimonate-containing solutions inside them.

With respect to the mechanism of accretional growth, WEINER and HOOD (1975), WADA (1980) suggested that negative charges in the repeating sequences (aligned at regular intervals) of the organic matrix may bind the $\mathrm{Ca}$ ion and serve as a template for mineralization in molluscs. WADA (1980) detected sulfur in the organic matrix involved in the initial mineralization of molluscs. He proposed that the negative charges on sulfate groups of acid mucopolysaccharide probably bind $\mathrm{Ca}$ ion, and then the crystal lattice structure can be built up. BÉLANGER (1960) showed that radioactive sulfur is incorporated into the otolithic organs of rats. LIM and ERWAY (1974) found that the synthesis of a metachromatic otoconial matrix, which is rapidly labeled by the incorporation of radioactive sulfur, precedes the appearance of otoconia in mice. SHRADER et al. (1973) reported that the appearance of otoconia in fetal mice was associated with metachromatic, PAS (periodic acidSchiff)-positive material that specifically incorporated radioactive sulfur. By contrast, manganese-deficient and pallid mice, which lack otoconia, formed a nonmetachromatic, variably PAS-positive matrix which incorporated little radioactive sulfur (SHRADER et al., 1973). In the present study, varying amounts of sulfur were found in the organic matrix of the otoconia and the otolithic membrane. This finding seems to support the abovementioned hypothesis proposed by WADA (1980). The low level of sulfur or its absence in the otolithic membrane may explain the fact that there are no otoconia in the otolithic membrane in spite of the deposition of Ca-containing precipitates. However, this remains a problem to be resolved in the future, since the X-ray microanalysis (EDS) used in the present study was not quantitative. In addition, the organic matrix is localized unevenly inside the otoconia and in the otolithic membrane.

Acknowledgements. The author is grateful to Mr. M. KAWAHARA for his technical assistance, and wishes to thank Prof. K. TAKAYA for his critical reading of the manuscript.

\section{REFERENCES}

Anniko, M.: Development of otoconia. Amer. J. Otolaryngol. 1: 400-410 (1980). 
Ballarino, J. and H. C. Howland: Otoconial morphology of the developing chick. Anat. Rec. 204: 83-87 (1982).

Balsamo, G., M. De Vincentis and F. Marmo: The effect of tetracyclin on the processes of calcification of the otoliths in the developing chick embryo. J. Embryol. Exp. Morphol. 22: 327-332 (1969).

BÉlAnger, L. F.: Development, structure and composition of the otolithic organs of the rat. In: (ed. by) R. F. SOGNNAES: Calcification in biological systems. American Association for the Advancement of Science, Washington, 1960 (p. 151-162).

Chitani, T.: Inorganic chemistry (In Japanese). Sangyotosho, Tokyo, 1959 (p. 233-234).

Fermin, C. D. and M. Igarashi: Development of otoconia in the embryonic chick (Gallus domesticus). Acta Anat. 123: 148-152 (1985).

HARADA, Y.: On the formation area of the otoconia (In Japanese). Equilibrium Res. 37: 217-220 (1978).

HaRADA, Y. and N. TAgashira: Metabolism of otoconia. Biomed. Res., Suppl. 2: 415-420 (1981).

KaWAmata, S.: Incorporation of strontium into the calcium carbonate crystals of the endolymphatic sac in the tree frog (Hyla arborea japonica). Anat. Rec. 218: 223228 (1987a).

: Growth aspects of calcium carbonate crystals of the endolymphatic sac in the tree frog (Hyla arborea japonica): A pulse-chase study. J. Electron Microsc. 36: 392-397 (1987b).

: Fine structural changes in the endolymphatic sac induced by calcium loading in the tree frog, Hyla arborea japonica. Arch. Histol. Cytol. 53: 397-404 (1990a).

Localization of pyroantimonate-precipitable calcium in the endolymphatic sac of the tree frog, Hyla arborea japonica. Arch. Histol. Cytol. 53: 405-411 (1990b).

LIM, D. J.: Formation and fate of the otoconia. Ann. Otol. Rhinol. Laryngol. 82: 23-35 (1973).

: The development and structure of the otoconia. In: (ed. by) I. FRIEDMANN and J. BALlantyne: Ultrastructural atlas of the inner ear. Butterworths, London, 1984 (p. 245-269).

LIM, D. J. and L. C. ERWAY: Influence of manganese on genetically defective otolith. Ann. Otol. Rhinol. Laryngol. 83: 565-581 (1974).

Mechigian, I., R. E. Preston, L.-G. Johnsson and J. SCHACHT: Incorporation of radioactive calcium into otolithic membranes of the guinea pig after aminoglycoside treatment. Acta Otolaryngol. (Stockh.) 88: 5660 (1979).
Nakahara, H. and G. Bevelander: An electron microscope study of crystal calcium carbonate formation in the mouse otolith. Anat. Rec. 193: 233-242 (1979).

Pannella, G.: Fish otoliths: Daily growth layers and periodical patterns. Science 173: 1124-1127 (1971).

Preston, R. E., L.-G. Johnsson, J. H. Hill and J. SchACHT: Incorporation of radioactive calcium into otolithic membranes and middle ear ossicles of the gerbil. Acta Otolaryngol. (Stockh.) 80: 269-275 (1975).

Ross, M. D.: Calcium ion uptake and exchange in otoconia. Adv. Otorhinolaryngol. 25: 26-33 (1979).

Ross, M. D. and D. R. Peacor: The nature and crystal growth of otoconia in the rat. Ann. Otol. Rhinol. Laryngol. 84: 22-36 (1975).

Shrader, R. E., L. C. Erway and L. S. Hurley: Mucopolysaccharide synthesis in the developing inner ear of manganese-deficient and pallid mutant mice. Teratology 8: 257-266 (1973).

VeEnhof, V. B.: The development of statoconia in mice. Akademie van Wetenschappen, Afd. Natuurkunde 2/58, No. 4. N. V. North-Holland Publ. Co., AmsterdamLondon, 1969.

WADA, K.: Initiation of mineralization in bivalve molluscs. In: (ed. by) M. OMORI and N. WATABE: The mechanisms of biomineralization in animals and plants. Tokai University Press, Tokyo, 1980 (p. 79-92).

WEINER, S. and L. Hood: Soluble protein of the organic matrix of mollusk shells: A potential template for shell formation. Science 190: 987-989 (1975).

WICK, S. M. and P. K. HePLER: Selective localization of intracellular $\mathrm{Ca}^{2+}$ with potassium antimonate. J. Histochem. Cytochem. 30: 1190-1204 (1982).

Dr. Seiichi KaWAmata

Department of Anatomy

Toyama Medical and Pharmaceutical University 2630 Sugitani, Toyama

930-01 Japan

川真田 聖 -

930-01 富山市杉谷 2630

富山医科薬科大学医学部

第二解剖学教室 